\title{
Acontecimentos importantes em Química há 50, 100, 150 ... anos
}

\section{Química Geral}

Há 750 anos, 1249

- Fundada a Universidade de Oxford.

Há 350 anos, 1649

- Schroeder descreve dois métodos para preparar arsénio metalico.

Há 250 anos, 1749

- Charles Wood descreve, pela primeira vez, de maneira aprofundada, o metal platina.

- Pierre Joseph Macquer edita a obra "Eléments de Chimie Theorique" com a qual difunde a química na época anterior a Lavoisier.

\section{Há 200 anos, 1799}

- Gilberts Annalen fundou a "Royal Institution of Great Britain".

- Joseph Priestley descobre o monóxido de carbono.

- Joseph Louis Proust investiga as razões ponderais contantes dos compostos químicos.

Há 150 anos, 1849

- Fundado o "Journal of the Chemical Society of London".

- Thomas Graham estuda a difusão dos líquidos.

- Auguste Bravais investiga a estrutura interna dos cristais.

Há 100 anos, 1899

- Criação da Comissão Internacional dos Pesos Atómicos.

- James Dewar prepara hidrogénio sólido.

- Herbert Smith constrói um goniómetro de três feixes para medir, e.g. ângulos em cristais e actividade óptica de cristais.

- William J. Pope e S. Peachey fazem o primeiro desdobramento de compostos de azoto, enxofre, estanho e telúrio nos seus compostos opticamente activos.

- Ernst Cohen demonstra a existência de três formas alotrópicas de elemento estanho. Até $20^{\circ} \mathrm{C}$ é estável o estanho cinzento, entre $20^{\circ} \mathrm{C}$ e $170^{\circ} \mathrm{C}$ é estável o estanho tetragonal e acima de $170{ }^{\circ} \mathrm{C}$ (até $232^{\circ} \mathrm{C}$ ) é estável o estanho ortorrômbico. Explica também o fenómeno "placa de estanho" que consiste na transformação, a baixa temperatura, do estanho branco em estanho cinzento.

- Hendrik Willem Bakhuis-Roozeboom e Albert Ladenburg, independentemente um do outro, demonstraram quando é que uma substância opticamente inactiva é uma mistura racémica ou uma mistura de compostos opticamente inactivos.

- Richard Abegg e Guido Bodländer tomam a afinidade electrónica como base de uma sistematização de compostos inorgânicos.

- Carl Engler e J Weissberg fazem a primeira sistematização dos compostos auto-oxidáveis com base no poder individual de adição do oxigénio molecular.

- Johannes Thiele apresenta os postulados da sua teoria parcial de valência.

- André Debierne isola o actínio, o novo metal radio-activo da pecheblenda (uranite).

- Marie Curie isola o chumbo radio-activo da pecheblenda e Jules Elster e Han F. K. Geitel demonstram a radioactividade potente deste isótopo do elemento recentemente descoberto - o polónio.

- Ernst Rutherford, Friedrich 0. Giesel e Henri Becquerel distinguem dois tipos de radiação "radio-activa": - raios $\alpha$ e $\beta$.

Há 50 anos, 1949

- Hans Werner Kuhn estende a teoria da cor incluindo modelos de gás de electrões.

\section{Química Tecnológica}

Há 200 anos, 1799

- Philippe Lebon regista uma patente sobre a produção de gás de carvão.

- Charles Tennant regista uma patente sobre a absorção de cloro gasoso por cal viva seca. Construiu uma fábrica em St Rollox para a preparação de lixívia. Durante muito tempo esta fábrica foi a maior do mundo.

- Franz Karl Achard funda uma fábrica para preparar açúcar de beterraba em Cunem (perto de Wroclaw).

Hâ 150 anos, 1849

- Foi testado o aço da fábrica Krupp.

- César Mansuete Despretz constrói um forno de chama eléctrica com eléctrodos crucíveis. crucible-electrodes.

- A P Halliday, em Salford, regista uma patente para a preparação de vinagre de madeira a partir de serradura, usando casca de carvalho e madeira pintada lixiviada.

- Max von Pettenkofer prepara gás de madeira e funda, dois anos mais tarde, com Ruland e V. Pauli um gerador de gás de madeira para a iluminação da estação de caminhos de ferro de Munique.

- Dubrunfaat e Leplay tentam introduzir a prática de extracção do açúcar do melaço com peróxido de bário.

- Jacques Joseph Ebelman prepara espinelas artificiais e outros minerais usando uma solução destes cristais em ácido bórico fortemente aquecida - evaporada.

- Agundre prepara uma pólvora "branca" a partir de clorato de potássio, prussiato (cianeto) de potassa e açúcar. Isto foi, durante muito tempo, um objectivo tecnológico muito importante na indústria de armamento.

\section{Há 100 anos, 1899}

- A "Deutsche Ammoniak Werke Gesellschaft", em Colónia, extrai amónia de lodos marinhos aquecendo a seco na presença de alcalinos ou alcalino-terrosos.

- Leonhard Lederer prepara o acetato de celulose por acção do ácido acético sobre hidrocelulose em presença de ácido sulfúrico. Este acetato de celulose é usado na manufactura de seda artificial (rayon).

- Em Oberbruch, perto de Aachen, são feitos fios de celulose usando o método do óxido de cobre-amoníaco.

- Em Oberbruch, perto de Aachen, Benjamin Talbot inventa um método para fazer aço a partir de ferro bruto.

- Harmet, em St Etienne, melhora o método de solidificação do aço líquido comprimindo-o a altas pressões.

- Charles Eduard Guilaume prepara uma liga de Ni-Fe "Inver" com um coeficiente de expansão muito baixo.

- Hülsberg, em Frankfurt/Main, inventa um método para preparar madeira à prova de fogo impregnando-a com ácido bórico e sulfato de amónio de um metal.

- Mac Dougall e Howles tenta pôr em prática a preparação do ácido nítrico provocando descargas eléctricas através do ar.

- Herman Frasch inventa um novo método para extrair enxofre de gesso contendo enxofre.

- Theodor Meyer propõe um processo melhorado de "câmara de chumbo" para a preparação do ácido sulfúrico.

- Aldolph Frank e Nikodem Caro preparam cianamida de cálcio aquecendo uma mistura de carbureto e de cal-viva com carbono em atmosfera de azoto. Esta cianamida de cálcio viria a ser utilizada como fertilizante.

- Hans Goldschmidt usa "thermit" (uma mistura de um óxido metálico e alumínio) para produzir, por exemplo, ferro para carris de caminhos de ferro ou componentes de máquinas. 
- P. Bergsoe em Copenhaga obtém uma patente sobre o método de extrair estanho dos lixos de folha de estanho.

- Bayer-Werke produz ácido acetil-salicílico sob o nome de "aspirina".

- Paul Sabatier e Jean Baptiste Sendérens descobrem a hidrogenação catalítica com níquel.

- H. Heraus funde grandes quantidades de quartzo num forno de oxi-hidrogénio de irídio a $1850^{\circ} \mathrm{C}$.

\section{Química Inorgânica}

Há 250 anos, 1749

- Pierre Joseph Macquer prepara o prussiato amarelo através da reacção de soda cáustica com Azul da Prússia.

\section{Há 200 anos, 1799}

- Joseph Priestley prepara monóxido de carbono num elevado grau de pureza.

François Chaussier e Louis Nicolas Vauquelin preparam hidrossulfito de sódio, que pode ser usado como agente destruidor de cloro.

Há 150 anos, 1849

- Henri Sainte-Claire-Deville preparou cristais de pentóxido de azoto por arrefecimento do gás a $-20^{\circ} \mathrm{C}$

- Paul Daubrée obteve óxido de estanho cristalino por reaç̧ão de cloreto de estanho e vapor de água num tubo de porcelana aquecido ao rubro.

- Friedrich Wöhler preparou nitretos metálicos directamente do azoto atmosférico e dos metais, por redução dos óxidos, com carbono, ao ar.

Há 100 anos, 1899

- Paul Walden usou dióxido de enxofre líquido como solvente para electrólitos e não-electrólitos.

- Ernst Cohen pesquisou os estados meta-estáveis dos metais e metalóides.

- Henri Moissan preparou fosforeto e arsenieto de cálcio por fusão do cálcio num forno eléctrico.

- Henri Moissan e Paul Lebau preparou hexafluoreto de enxofre gasoso (a partir de flúor e enxofre). A - $55^{\circ} \mathrm{C}$ esta substância transforma-se num sólido cristalino. Com este resultado, eles provaram que o enxofre pode também apresentar a valencia 6 .

- Adolph Frank preparou grafite por reação de monóxido ou dióxido de carbono com carburetos metálicos a altas temperaturas.

Há 50 anos, 1949

- $\mathrm{C}$ Grube et al. prepararam o subóxido de alumínio, $\mathrm{Al}_{2} \mathrm{O}$.

Química-Física e Electroquímica

Há 200 anos, 1799

- Alessandro Volta desenvolve a sua pilha eléctrica.

Há 150 anos, 1849

- Gustav Wiedemann demonstra a existência de relação entre a condutividade eléctrica e a estrutura dos cristais.

- Herman Kolbe faz a electrólise de sais de ácidos gordos produzindo radicais.

Há 100 anos, 1899

- Arthur Hantzsch desenvolve o conceito de isomerismo de ionização, pseudo-ácidos e pseudo-bases e avança com a determinação da constituição de compostos tautoméricos.

- Harold A Wilson determina a velocidade de iões em chamas contendo sais vaporizados.
- Philipp Lenard observa que o oxigénio é ozonizado pela radiação ultravioleta.

- Gustav Tainmann realiza medidas de grande precisão no que respeita à influência de pressões muito elevadas sobre a alteração dos calores de fusão de cerca de 30 compostos.

- Mahler melhora a bomba calorimétrica de Berthelot (1879) usando um cilindro de aço esmaltado em lugar de um de platina.

- Manlay inventa a ozotipo (impressão de positivos fotográficos), um processo fotográfico utilizando papéis recobertos com uma mistura de dicromato de potássio e gelatina.

Há 50 anos, 1949

- Ronald George Wreyford Norrish e George Porter desenvolvem a fotólise de relâmpago (flash photolysis).

- William Giaugue recebe o Prémio Nobel da Química pelos seus estudos de termodinâmica a muito baixas temperaturas.

\section{Química Analítica}

Há 250 anos, 1749

- Caspar Neumann editou "Chymial Medicinae dogmatico experimentalis, Tom primi; Pars prima et secunda", que lança as bases da acidimetria.

Há 150 anos, 1849

- Lyon Playfair obtém nitroprussieto de sódio por reacção de ácido nitroso e prussiato vermelho. Esta substância é um reagente muito sensivel aos sulfuretos alcalinos, formando um lindo produto púrpura.

Há 50 anos, 1949

- Th. Wieland et al descobrem um método de cromatografia em papel para a determinação quantitativa de amino-ácidos com cobre radioactivo.

\section{Bioquímica}

Há 300 anos, 1699

- Simon Bouldec introduz um método de extracção para a análise de plantas. Ele aplica isto na investigação comparativa de classes de ipecacuanha. Tal como a palavra extracção indica, ele usa água e vinho espirituoso.

\section{Há 200 anos, 1799}

- Antoine Francis de Fourcroy e Louis Nicolas Vauquelin preparam ureia pura como produto final da conversão de proteínas nos corpos animais.

Há 150 anos, 1849

- Ebenhezer N Horford descobre um método para evaporar leite.

- Bleunard prepara alanina como um produto da separação da legamina das ervilhas.

Há 100 anos, 1899

- Jacques Loeb consegue a fertilização química (com cloreto de magnésio) de ovos de ouriços do mar.

- Albrecht Kossel formula a sua teoria da protamina.

- Martin Jacoby conclui que no caso de diabetes grave não ocorre glicólise.

- Cl. Fermi usa alguns fungos de fissão para produzir enzimas proteolíticas. Estas enzimas transformam proteínas, tais como glutén e fibrina, em compostos solúveis. Assim, são capazes de compor protoplasma.

- W Spitzer consegue transformar hipoxantina e xantina em ureia usando extractos de órgãos (eg. baço e fígado de vitela e de vaca). 
Há 50 anos, 1949

- Louis Frederick Fieser e Mary Fieser publicam a $3^{a}$ edição de "Natural Products related to Phenanthrene".

- Edward Calvin Kendall et al. descobre a cortisona como um medicamento especial para a artrite reumatóide.

- Wolfgang Langenbeck investiga as relações entre catalisadores orgânicos e enzimas.

Richard Kuhn investiga alguns problemas da bioquímica genética. Adolf Butenandt, W Weidel e H Schlossberger determinam que os pre-requisitos de fermentos específicos são os genes $\mathrm{V}+\mathrm{e}$ en- que promovem eg. a formação de pigmentos omocrómicos por catálise ou o metabolismo do triptofano.

Karl Johann Freudenberg descobre a formação de substâncias idênticas à lignina em condições fisiológicas.

Gustaf Ehrhardt discobre uma nova classe de analgésicos relacionada com o difenilmetano.

\section{Química Farmacêutica}

Há 600 anos, 1399

- Os Visconti, em Milão, levam a cabo a primeira desinfecção imposta por lei para os doentes de peste e, 4 anos mais tarde, é fundada a primeira instituição para quarentena.

\section{Há 200 anos, 1799}

- Valentin Rose Jr. é co-autor do primeiro livro de medicina na Prússia, Edição do Manual de Utilidades Farmaceuticas, um livro de texto sobre o conhecimento farmacológico em língua alemã.

- Edição da Pharmacopoea Borussica Edition 1.

Morre Ernst Wilhlem Martiues, farmacêutico da corte e professor em Erlangen.

Humphry Davy descobre a acção anestésica do óxido nitroso (gás hilariante), com o qual Horac Wells em 1844 consegue a primeira narcose.

\section{Há 150 anos, 1849}

Fundação da "Süddeutschen Apothekersverein" (Sociedade dos Farmacêuticos na Alemanha do Sul).

\section{Há 100 anos, 1899}

Weiss, em Basel, descobre que usando ácido da china na alimentação a quantidade de ureia excretada diminui. Este facto conduz à introdução de algumas preparações à base de ácido da china em medicina p.ex. sidonais (piperazina de ácido da china) e urosinas (sais de lítio de ácido da china).

Heinrich Dreser adiciona o ácido acetilsalicílico à lista de medicamentos sob o nome de aspirina $($ acetil + spir (ácido $)+$ in $)($ spiracic $=$ antigo nome do ácido salicílico).

\section{Química Orgânica}

\section{Há 250 anos, 1749}

Andreas Sigismund Marggraf obtém um concentrado de ácido fórmico por destilação de formigas vermelhas.

\section{Há 200 anos, 1799}

Franz Karl Achard funda a primeira fábrica de açúcar de beterraba. Martin Heinrich Klaproth isola o ácido melítico a partir de mel mineralizado.

\section{Há 150 anos, 1849}

\section{Adolph Wartz descobre as alquilaminas.}

Eduard Frankland prepara alcanos por reacção de alquiliodetos com zinco e isola os compostos organometálicos metil-zinco e etil-zinco pensando também ter descoberto os radicais livres metilo e etilo.
Herman Kolbe propõe a síntese de alcanos por electrólise de ácidos gordos: "Síntese de Kolbe".

Charles Mansfield sintetiza o benzeno tratando nitrobenzeno com ácido nítrico.

\section{Há 100 anos, 1899}

Adolf von Baeyer e Victor Villiger oxidam cetonas a ésteres usando perácidos - "oxidação de Baeyer-Villiger" - e preparam peróxidos e perácidos orgânicos tais como o perácido benzóico e o monoperácido ftálico.

Johannes Thiele formula a "Hipótese de Valência Parcial" relativa a ligações carbono-carbono duplas e triplas, explicando a sua particular reactividade.

John Norman Collie e Thomas Tickle demonstram que o dimetilpirão forma produtos de adição muito estáveis com ácidos hidro-halogénicos e tartáricos, entre outros. Esta reactividade é explicada assumindo a tetravalência do oxigénio. Os compostos em causa foram denominados sais de oxónio por serem considerados derivados da hipotética base $\mathrm{H} 30 . \mathrm{OH}$ (hidroxilo de oxónio).

Georg Wagner e Hans Meerwein conseguem a inversão de monoterpenos dicíclicos (e.g. pineno em canfeno): "inversão de WagnerMeerwein".

Paul Sabatier e Jean-Baptiste Sendérens realizam a hidrogenação de compostos insaturados, usando níquel como catalisador.

Paul Walden demonstra a "inversão de Walden", segundo a qual um isómero óptico é convertido num derivado do isómero inverso por acção de determinados reagentes. Por exemplo o tratamento de ácido málico com $\mathrm{PCl} 5$ origina o ácido 1-clorosuccínico, que por sua vez pode ser convertido no ácido 1- málico succínico por acção do óxido de prata.

Ludwig Knorr sintetiza o ácido "diacenlamber" a partir de ácido acetilacético e sódio.

Emil Erlemeyer Jr. sintetiza e separa a (benzoil) tirosina.

W Marckwald e Alex McKenzie efectuam várias sínteses assimétricas.

E Wedekind demonstra a assimetria do átomo de azoto pentavalente, a activação óptica e a auto-racemização.

W.J. Pope e S.J. Peachy separam -benzil-fenil-alquilmetil amónio nos antípodas ópticos por cristalização de sulfonatos de cânfora.

Traugott Sandmever prepara hidrocarbo-difenilimida a partir de tiocabanilida e hexanida de potássio com chumbo branco. Este composto constitui a base do indigo.

Há 50 anos, 1949

Hans Werner Kuhn desenvolve a teoria das cores dos compostos orgânicos.

E R Alexander e E E Eliel obtêm compostos opticamente activos com deutério e hidrogénio.

Kenyon e M P Balfe conseguem a separação óptica do o-tolil-p-tolil carbinol.

Patil Niggli edita "Grandlagen der Stereochernie" (Princípios da Estereoquímica).

A Skita sintetiza estereoisómeros de amino-álcoóis do tipo efedrina. M C Rebstock et al descrevem a síntese e explicam a estrutura do cloro-anfenical.

Adolf Butanandt, H. Hellmann e E. Renz melhoram a síntese do D, 1-triptofano.

Wolfgang Langenbeck pesquisa a aceleração da condensação do formaldeído por catalisadores orgânicos.

Otto Warburg edita "Wasserstoffübertragende Ferment" (Enzimas transportadores de hidrogénio).

Wilhelm Schenk Jr. investiga química e cristalograficamente compostos de adição da ureia.

R Winzinger-Aust propõe um novo método de preparação de sais corados de tri-arilpirílio.

Otto Bayer pesquisa a química dos acrilonitrilos.

Walter Reppe investiga a química do acetileno e do monóxido de carbono.

Saunders estuda os compostos aromáticos diazo e as suas aplicações técnicas.

Rudolf Criegll estuda a constituição de peróxidos e ozomidas. 


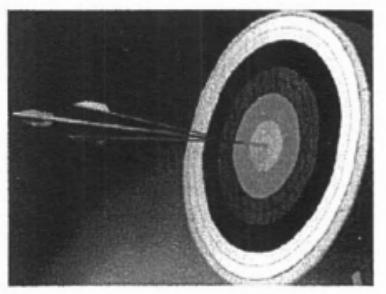

Espectrómetros para ánalise química.

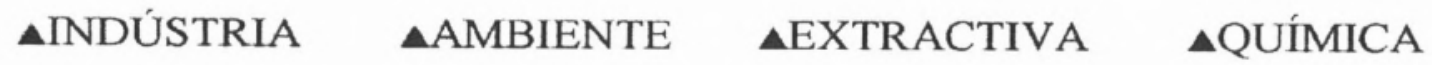

Emissão óptica

ICP - Tecnologia CCD*

$120-800 \mathrm{~nm}$

Sistema óptico circular

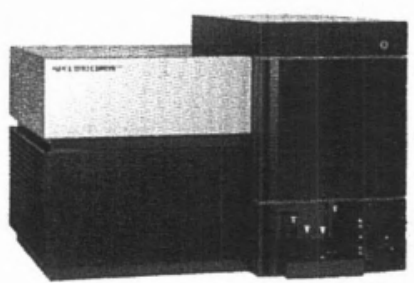

Faísca

Para a indústria metalúrgica e metalomecânica $120-800 \mathrm{~nm}$

Opção: Sistema Mapping com varrimento da superfície da amostra para deteç̧ão de inclusões e segregação em metais.

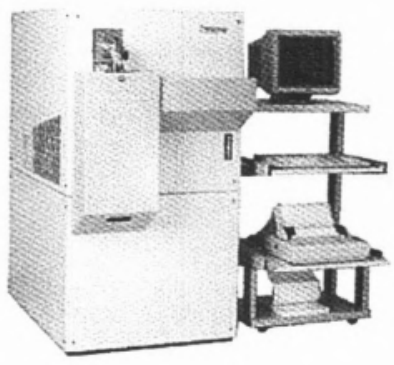

\section{Raio-X}

Por fluorescência, de energia dispersiva polarizada (EDXRF)

\section{Glow discharge}

Para a análise química e análise superficial (tratamentos térmicos e superficiais metálicos)

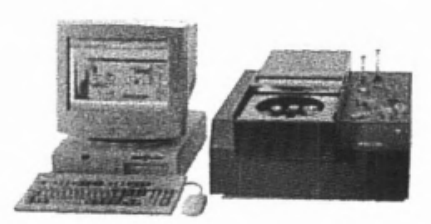

\section{Mais de $\mathbf{4 0}$ unidades instaladas.}

Tecnologia alemã a preços económicos.

*Estamos a organizar um seminário

Para inscrições, favor contactar-nos.

\section{Importador exclusivo:}

